\title{
Factors associated with current and severe pain among people living with HIV: results from a statewide sample
}

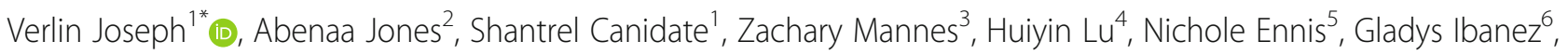
Charurut Somboonwit ${ }^{7}$ and Robert Cook $^{1}$

\begin{abstract}
Background: People living with HIV (PLHIV) are more likely to suffer from pain compared to the general public. Pain often clusters with mental health symptoms and substance use. This study sought to evaluate mental health and substance use factors associated with any pain and severe pain intensities among PLHIV.

Methods: Data were derived from HIV+ adults $(N=733)$ recruited from community health centers across Florida who completed questionnaires regarding demographics, chronic pain, HIV clinical outcomes, mental health symptoms, and substance use information. Pain was assessed using the Brief Pain Inventory (BPI) short form. Multivariate logistic regression analysis was utilized to assess the relationship between selected covariates and pain.

Results: Approximately half (45.0\%) of participants reported having any current pain while $16.1 \%$ reported severe pain. The odds of having any current pain were 2.49 (CI 95\% 1.48, 4.18, $p<0.01$ ) times greater among PLHIV reporting anxiety and 1.69 (CI 95\% 1.11, 2.57, $p=0.01$ ) times greater among PLHIV reporting PTSD compared to those without those factors. The odds of having severe pain were 2.03 (CI 95\% 1.03, 4.01, $p=0.04)$ times greater among PLHIV reporting anxiety and $2.02(\mathrm{Cl} 95 \% 1.26,3.24, p<0.01)$ times greater among female participants compared to PLHIV without those factors respectively. Factors including depression, alcohol consumption, and marijuana use were not statistically associated with any current pain nor with severe pain.

Conclusion: The relationship between pain and mental health is complex. Thus, future research is needed to determine if pain treatments may reduce mental health symptoms or if treatments can be targeted to address both issues simultaneously.
\end{abstract}

Keywords: Marijuana, Pain, PLHIV, Mental health, Substance use

\section{Background}

Advancements in antiretroviral therapy (ART) have increased the life expectancy among people living with HIV/AIDS (PLHIV) and have transformed the once fatal disease into a serious chronic illness [1]. As a result,

\footnotetext{
* Correspondence: verlinwjoseph@ufl.edu

'Department of Epidemiology, College of Public Health and Health Professions \& College of Medicine, University of Florida, P.O. Box 100231, 2004 Mowry Road, Gainesville, FL 32610, USA

Full list of author information is available at the end of the article
}

researchers have shifted their focus to developing a greater understanding of the quality of life among PLHIV within the psychosocial context of chronic pain [2-4]. PLHIV are more likely to suffer from pain associated with musculoskeletal disorders, neuropathic pain, and headache disorders than the general population [5, 6]. Additionally, PLHIV reporting severe pain are more likely to report missed clinic visits compared to PLHIV without pain [7]. As such, identifying factors associated

(c) The Author(s). 2020 Open Access This article is licensed under a Creative Commons Attribution 4.0 International License, which permits use, sharing, adaptation, distribution and reproduction in any medium or format, as long as you give appropriate credit to the original author(s) and the source, provide a link to the Creative Commons licence, and indicate if changes were made. The images or other third party material in this article are included in the article's Creative Commons licence, unless indicated otherwise in a credit line to the material. If material is not included in the article's Creative Commons licence and your intended use is not permitted by statutory regulation or exceeds the permitted use, you will need to obtain permission directly from the copyright holder. To view a copy of this licence, visit http://creativecommons.org/licenses/by/4.0/. The Creative Commons Public Domain Dedication waiver (http://creativecommons.org/publicdomain/zero/1.0/) applies to the data made available in this article, unless otherwise stated in a credit line to the data. 
with pain may serve as a crucial first step in improving the quality of life and clinical outcomes among PLHIV.

In addition to chronic pain, PLHIV have also reported mental health and harmful substance use issues $[6,8]$. Generally, PLHIV experiencing mental health problems such as anxiety and depression are also more likely to report increases in pain $[9,10]$. Traditionally, clinicians have often prescribed opioids to treat pain for PLHIV [11]; however, PLHIV are more likely to report high levels of pain even when using prescription opioids, which have become the leading sources of prescription drug abuse [12-15]. PLHIV reporting substance use and depression are more likely to report a lower quality of life compared to non-users [16]. However, research examining the intersection of substance abuse, mental health, and pain remains limited $[6,10,17]$. Thus, continued research is needed to understand the associations between clustering mental health and substance use factors and pain severity.

Generally, studies examining clustering mental health and substance use factors do not include pain severity [18-20]. Therefore, further research is needed to determine which specific patterns of substance use and mental health predictors are associated with pain. Understanding the intersection of mental health and substance use in the context of pain is vital for developing interventions aligned with the White House's National HIV/AIDS Strategy of improving health outcomes for PLHIV [21]. Further, identifying factors associated with pain may inform strategies that seek to improve quality of life and improve clinical outcomes among PLHIV [22, 23]. One shared limitation of previous studies targeting pain and substance use among PLHIV was the inability to control for the peak-end phenomenon. The peak-end phenomenon occurs when participants recall the worst pain intensity scores when queried about average pain intensity ratings [24]. As such, it is crucial to include worst pain intensity ratings when studying correlates of pain. Thus, we specifically sought to examine: 1) the prevalence of any current pain and severe pain in a statewide sample of PLHIV; 2) mental health conditions and substance use factors associated with any current pain and with severe pain in PLHIV.

\section{Methods}

\section{Study design}

The Florida Cohort Study is an ongoing statewide prospective longitudinal study that seeks to identify factors that influence health outcomes in PLHIV. This study is an analysis of cross sectional data collected among PLHIV living in Florida. The protocol was approved by the Institutional Review Boards (IRBs) at the University of Florida and the Florida Department of Health (DoH). All participants provided written informed consent as well as signed the Health Insurance Portability and Accountability Act (HIPPA) authorization form for use of their protected medical information.

Eligible participants were adults 18 years or older with a diagnosis of HIV. Participants were recruited from multiple cities in Florida (Gainesville, Ft. Lauderdale, Lake City, Miami, Orlando, Sanford, Tampa, and Wildwood) from 2014 to 2017. The study team's recruitment efforts entailed posting brochures at community clinics and county health departments, having clinic/facility staff members reach out to potential participants, and consulting patient registries.

\section{Measures}

Participants completed study questionnaires during study enrollment. The questionnaire was developed for this study and has been made available online [25]. Data on demographics, HIV clinical outcomes, mental health, and the use of substances including alcohol, illicit drugs, and marijuana were obtained by self-report. Demographic variables included age, gender at birth (i.e., male or female), race/ethnicity (non-Hispanic Black, Hispanic, and non-Hispanic White), and employment status (employed or unemployed).

The questionnaire inquired about current and lifetime substance use of marijuana, alcohol, injection drug use (IDU), and crack/cocaine. Individuals who indicated having used marijuana during the past 3 months were categorized as current users while individuals abstaining from marijuana use were categorized as nonusers. Participants indicating any IDU or crack/cocaine use during the past year or during any period of time were categorized as lifetime users. Hazardous drinking was defined in concordance with the National Institute on Alcohol Abuse and Alcoholism (NIAAA) definition as consuming $\geq 14$ drinks per week or $\geq 5$ drinks per occasion at least monthly for men and $\geq 7$ drinks per week or $\geq 4$ drinks per occasion at least monthly for women [26].

Based on their self-reported reasons for use, participants who used marijuana were divided into two groups any recreational use and medicinal use only. In this study, recreational use was defined as using marijuana for the purpose of getting high or stoned, increasing libido/improving sexual performance, or fitting into social situations, while medicinal marijuana use was defined as using marijuana for the purpose of improving appetite/ gaining weight, inducing sleep, relieving nausea/vomiting, relieving pain, or relieving anxiety/depression/stress. Participants reporting marijuana use for both recreational and medicinal purposes were classified as recreational users. This distinction was made due to prior research suggesting a variety of motives for marijuana use depending on recreational or medicinal use) [27]. 
This study employed the Brief Pain Inventory short form (BPI-SF) [28] to assess the severity of the participants' pain and to examine the impact of the experienced pain on each participant's daily functioning. Using a scale of 1-10, participants were asked to rate their level of pain intensity, other than common pains, during the previous $24 \mathrm{~h}$, identifying the pain level at its worst, least, average, and current. In concordance with the BPI user guide, the average of the four pain level intensity scores reported by the participant provided a composite pain score [29]. PLHIV that did not report any pain during the previous $24 \mathrm{~h}$ was categorized as having no current pain. Participants with an average score of $\geq 1$ were categorized as having any current pain [30]. In order to account for the peak-end phenomenon, we utilized a cut-off score for worst pain of $\geq 6$ in the secondary analysis of severe pain [24].

The Generalized Anxiety Disorder Scale (GAD-7) was used to assess participants' levels of anxiety. The GAD-7 is composed of seven items that screen for the presence of an anxiety disorder. Based on their responses, participants were dichotomized as having no symptoms of anxiety (score 0-9) or current anxiety symptoms (scores 210) [31].

Participants also completed the Patient Health Questionnaire (PHQ-8), consisting of 8 items to assess the frequency of depressive symptoms among the participants. Scores can range from 0 to 24 , and participants were categorized as having no current depression symptoms (score 1-9), or current depressive symptoms (score $\geq 10$ ). The PHQ-8 has demonstrated high reliability and is a well-validated measure for assessing depressive symptoms among PLHIV [32].

The Primary Care Post Traumatic Stress Disorder Screener (PC-PTSD), which contains 4 items, is a selfreported questionnaire designed to assess symptoms of PTSD. Individuals indicating one or more symptom(s) were coded as positive for PTSD symptoms [33].

\section{Statistical analyses}

Data were analyzed using SAS ${ }^{\mathrm{TM}}$ (Statistical Analysis Software) version 9.4 (SAS Institue Inc., Cary, NC). First, we assessed the bivariate relationships of mental health conditions, substance use, and sociodemographic factors associated with pain. For the purposes of this analysis, age was dichotomized 18-49 and $\geq 50$ years to improve interpretation of the results. We utilized simple logistic regression modeling to report the unadjusted odds ratios and $p$-values of the associations between these factors and pain scores. Variables that were statistically significant $(p<.05)$ in the bivariate analysis were included in the multivariable model. We then used a multivariate logistic regression to distinguish the relationship between mental health, substance use, sociodemographic factors, and any pain. In this multivariate logistic regression model, no pain was assigned as the referenced pain level. We then used a multivariate logistic regression to distinguish the relationship between mental health, substance use, and sociodemographic factors associated with severe pain. In this multivariate logistic regression model, the reference category was pain scored between 0 and 6 . All data analyses were conducted using SAS version 9.4.

\section{Results}

The goal of this analysis was to report the prevalence of pain and identify correlates of pain among PLHIV. A total of 733 PLHIV enrolled in the Florida Cohort Study completed the study assessments (Table 1). Roughly half (45.0\%) of our sample reported pain in the previous 24 h. Additionally, 118 (16.1\%) participants reported severe pain in the previous $24 \mathrm{~h}$. Overall, 426 (58.1\%) participants were aged between 18 and 49, and 307 (41.9\%) were in the age group of 50 years and older. Furthermore, $500(68.2 \%)$ of participants were men and 233 (31.8\%) were women. Among the participants who completed the demographic assessment, 403 (57.3\%) were black and roughly $73.8 \%$ were unemployed.

\section{Mental health factors and any current pain}

Differences in mental health symptoms between participants without any current pain and any pain are summarized in Table 1. Among PLHIV reporting any current pain, $63.9 \%$ experienced current symptoms of anxiety as compared to $36.1 \%$ who did not report current anxiety $(p<0.01)$. Also, among PLHIV experiencing any current pain, $59.4 \%$ reported current symptoms of depression compared to $37.4 \%$ that did not $(p<0.01)$. Likewise, $62.4 \%$ of PLHIV with current pain reported symptoms of PTSD while $38.4 \%$ did not report symptoms of PTSD $(p<0.01)$.

\section{Mental health factors and severe pain}

Differences in mental health factors associated with severe pain are summarized in Table 2. Among PLHIV reporting severe pain, $27.4 \%$ experienced current symptoms of anxiety as compared to $10.5 \%$ that did not $(p<0.01)$. Among participants reporting severe pain, $26.6 \%$, reported current symptoms of depression compared to $10.8 \%$ of that did not $(p<0.01)$. Similarly, $27.2 \%$ of participants with severe pain reported symptoms of PTSD compared to $11.5 \%$ that did not $(p<0.01)$.

\section{Substance use factors and any current pain}

Additionally, substance use factors associated with any current pain among PLHIV are summarized in Table 1. Of those PLHIV who reported any current pain, 56.7\% used marijuana for therapeutic reasons, $43.5 \%$ used marijuana for recreational reasons, and $42.9 \%$ did not 
Table 1 Demographic Mental Health and Substance Use Characteristics of Any Current Pain Among PLHIV N=733

\begin{tabular}{|c|c|c|c|c|}
\hline Characteristics & $\begin{array}{l}\text { No Pain } \\
N=403(56.0 \%)\end{array}$ & $\begin{array}{l}\text { Any Pain } \\
N=330(45.0 \%)\end{array}$ & Unadjusted Odds Ratio & $P$ Value \\
\hline Age in Years & & & & $<0.01$ \\
\hline $18-49(n=426)$ & $255(59.9)$ & $171(40.1)$ & ref & \\
\hline$\geq 50(n=307)$ & $148(48.2)$ & $159(51.8)$ & $1.60(1.19,2.15)$ & \\
\hline Sex & & & & 0.11 \\
\hline Male $(n=500)$ & $285(57.0)$ & $215(43.0)$ & ref & \\
\hline Female $(n=233)$ & $118(50.6)$ & $115(49.4)$ & $1.29(0.95,1.77)$ & \\
\hline Race/ethnicity & & & & 0.15 \\
\hline Non-Hispanic Black $(n=403)$ & $222(55.1)$ & $181(44.9)$ & ref & \\
\hline Non-Hispanic White $(n=157)$ & $77(49.0)$ & $80(51.0)$ & $0.81(0.55,1.20)$ & \\
\hline Hispanic $(n=143)$ & $86(60.1)$ & $57(39.9)$ & $1.27(0.88,1.84)$ & \\
\hline Employment & & & & $<0.01$ \\
\hline Employed $(n=188)$ & $128(68.1)$ & $60(31.9)$ & ref & \\
\hline Unemployed $(n=529)$ & $266(50.3)$ & $263(49.7)$ & $2.11(1.49,3.00)$ & \\
\hline Anxiety (GAD-7) & & & & $<0.01$ \\
\hline No $(<10)(n=493)$ & $315(63.9)$ & $178(36.1)$ & ref & \\
\hline Yes $(\geq 10)(n=219)$ & $79(36.1)$ & $140(63.9)$ & $3.14(2.25,4.37)$ & \\
\hline Depression (PHQ-8) & & & & $<0.01$ \\
\hline No $(<10)(n=492)$ & $308(62.6)$ & $184(37.4)$ & ref & \\
\hline Yes $(\geq 10)(n=229)$ & $93(40.6)$ & $136(59.4)$ & $2.45(1.78,3.37)$ & \\
\hline Post-Traumatic Stress Disorder (PC-PTSD) & & & & $<0.01$ \\
\hline No $(n=511)$ & $315(61.6)$ & $196(38.4)$ & ref & \\
\hline Yes $(n=202)$ & $76(37.6)$ & $126(62.4)$ & $2.66(1.90,3.73)$ & \\
\hline Marijuana Use & & & & 0.03 \\
\hline No $(n=466)$ & $266(57.1)$ & $200(42.9)$ & ref & \\
\hline Recreational use $(n=147)$ & $83(56.5)$ & $64(43.5)$ & $1.03(0.71,1.49)$ & \\
\hline Therapeutic use $(n=104)$ & $45(43.3)$ & $59(56.7)$ & $1.74(1.14,2.68)$ & \\
\hline Alcohol Consumption & & & & 0.47 \\
\hline No Drinking $(n=192)$ & $112(58.3)$ & $80(41.7)$ & ref & \\
\hline Non-Hazardous Drinking $(n=257)$ & $140(54.5)$ & $117(45.5)$ & $1.17(0.80,1.71)$ & \\
\hline Hazardous Drinking $(n=255)$ & $134(52.6)$ & $121(47.5)$ & $1.26(0.87,1.85)$ & \\
\hline Lifetime Injection drug use & & & & 0.09 \\
\hline No $(n=611)$ & $346(56.6)$ & $265(43.4)$ & ref & \\
\hline Yes $(n=101)$ & $48(47.5)$ & $53(52.5)$ & $1.44(0.95,2.20)$ & \\
\hline Lifetime Crack/Cocaine & & & & 0.86 \\
\hline No $(n=625)$ & $340(54.7)$ & $281(42.3)$ & Ref & \\
\hline Yes $(n=102)$ & $54(53.5)$ & $47(46.5)$ & $1.05(0.69,1.61)$ & \\
\hline
\end{tabular}

currently use marijuana $(p=0.01)$. Substances including hazardous drinking, lifetime injection drug use, and lifetime crack/cocaine use were not statistically associated with any current pain at the bivariate level.

\section{Substance use factors and severe pain}

Substance use factors associated with severe pain among PLHIV are summarized in Table 2. Among PLHIV reporting severe pain, $22.1 \%$ used marijuana for therapeutic reasons, $17.0 \%$ used marijuana for recreational reasons, and $14.2 \%$ did not currently use marijuana $(p=0.04)$.
Substances including hazardous drinking, lifetime injection drug use, and lifetime crack/cocaine use were not statistically associated with severe pain at the bivariate level.

\section{Sociodemographic factors and any pain}

Those PLHIV reporting pain were more likely to be age 50 years or older $(51.8 \%)$ compared to PLHIV between 18 and 49 years old $(40.1 \%)(p<0.01)$. PLHIV reporting being unemployed (49.7\%) were also more likely to report having pain compared to employed individuals $(31.9 \%)(p<0.0001)$. Additionally, female participants 
Table 2 Demographic Mental Health and Substance Use Characteristics of Severe Pain Among PLHIV N=733

\begin{tabular}{|c|c|c|c|c|}
\hline Characteristics & $\begin{array}{l}\text { Non-Severe Pain } \\
N=615(83.9 \%)\end{array}$ & $\begin{array}{l}\text { Severe Pain } \\
N=118(16.1 \%)\end{array}$ & Unadjusted Odds Ratio & $P$ Value \\
\hline Age in Years & & & & 0.03 \\
\hline $18-49(n=426)$ & $368(86.4)$ & $58(13.6)$ & ref & \\
\hline$\geq 50(n=307)$ & $247(80.6)$ & $60(19.5)$ & $1.54(1.04,2.29)$ & \\
\hline Sex & & & & $<0.01$ \\
\hline Male $(n=500)$ & $435(87.0)$ & $65(13.0)$ & ref & \\
\hline Female $(n=233)$ & $180(77.3)$ & $53(22.6)$ & $1.97(1.32,2.95)$ & \\
\hline Race/ethnicity & & & & $<0.01$ \\
\hline Non-Hispanic Black $(n=403)$ & $324(80.4)$ & $79(19.6)$ & ref & \\
\hline Non-Hispanic White $(n=157)$ & $139(88.5)$ & $18(11.5)$ & $0.53(0.31,0.92)$ & \\
\hline Hispanic $(n=143)$ & $128(21.7)$ & $15(13.4)$ & $0.48(0.27,0.87)$ & \\
\hline Employment & & & & $<0.01$ \\
\hline Employed $(n=188)$ & $174(92.6)$ & $14(7.4)$ & ref & \\
\hline Unemployed $(n=529)$ & $427(80.7)$ & $102(19.3)$ & $2.97(1.65,5.33)$ & \\
\hline Anxiety (GAD-7) & & & & $<0.01$ \\
\hline No $(<10)(n=493)$ & $441(89.5)$ & $52(10.5)$ & ref & \\
\hline Yes $(\geq 10)(n=219)$ & $159(72.6)$ & $60(27.4)$ & $3.20(2.12,4.83)$ & \\
\hline Depression (PHQ-8) & & & & $<0.01$ \\
\hline No $(<10)(n=492)$ & $439(89.2)$ & $53(10.8)$ & Ref & \\
\hline Yes $(\geq 10)(n=229)$ & $168(73.4)$ & $61(26.6)$ & $3.01(2.00,4.53)$ & \\
\hline Post-Traumatic Stress Disorder (PC-PTSD) & & & & $<0.01$ \\
\hline No $(n=511)$ & $452(88.5)$ & $59(11.5)$ & ref & \\
\hline Yes $(n=202)$ & $147(72.8)$ & $55(27.2)$ & $2.87(1.90,4.73)$ & \\
\hline Marijuana Use & & & & 0.10 \\
\hline No $(n=466)$ & $400(85.8)$ & $66(14.2)$ & ref & \\
\hline Recreational use $(n=147)$ & $122(83.0)$ & $25(17.0)$ & $1.24(0.75,2.05)$ & \\
\hline Therapeutic use $(n=104)$ & $81(77.9)$ & $23(22.1)$ & $1.72(1.01,2.93)$ & \\
\hline Alcohol Consumption & & & & 0.31 \\
\hline No Drinking ( $n=192)$ & $165(85.9)$ & $27(14.1)$ & ref & \\
\hline Non-Hazardous Drinking ( $n=257)$ & $219(85.2)$ & $38(14.8)$ & $1.06(0.62,1.81)$ & \\
\hline Hazardous Drinking $(n=255)$ & $207(81.2)$ & $48(18.8)$ & $1.42(0.85,2.37)$ & \\
\hline Lifetime Injection drug use & & & & 0.62 \\
\hline No $(n=611)$ & $514(84.1)$ & $97(15.9)$ & ref & \\
\hline Yes $(n=101)$ & $83(82.2)$ & $18(17.8)$ & $1.15(0.66,2.00)$ & \\
\hline \multicolumn{5}{|l|}{ Lifetime Crack/Cocaine } \\
\hline No $(n=625)$ & $524(83.8)$ & $101(16.2)$ & Ref & 0.90 \\
\hline Yes $(n=101)$ & $85(83.3)$ & $17(16.7)$ & $1.04(0.59,1.82)$ & \\
\hline
\end{tabular}

(49.4\%) and non-Hispanic White PLHIV (51.0\%) reported greater proportions of pain than their male and non-Hispanic Black counterparts respectively. However, race/ethnicity was not statistically significant at the bivariate level.

\section{Sociodemographic factors and severe pain}

Those PLHIV reporting severe pain were more likely to be aged 50 years or older (19.5\%) compared to PLHIV between ages year old 18-49 (13.6\%) $(p<0.01)$. Additionally, $19.6 \%$ of non-Hispanic Black participants reported severe pain compared to $13.5 \%$ of Hispanic and $11.5 \%$ of non-Hispanic White participants $(p<0.01)$. Female participants $(22.6 \%)$ were more likely to report severe pain compared to male participants $(13.0 \%)(p<$ 0.01). Unemployed PLHIV (19.3\%) were also more likely to report having severe pain compared to employed PLHIV (7.4\%) $(p<0.01)$.

Any current pain vs. no pain

Results of the adjusted odds ratios for the association of selected mental health, substance use, and 
sociodemographic factors with any pain are presented in Table 3. Any current pain was significantly more common in participants $\geq 50$ years of age $(\mathrm{AOR}=1.73$; CI 95\% 1.23, 2.45, $p<0.01$ ), females (AOR $=1.47$; CI 95\% $1.01,2.12, p=0.04)$, and unemployed participants $(\mathrm{AOR}=1.63$; $\mathrm{CI} 95 \% 1.08,2.45, p=0.02)$ than PLHIV without those sociodemographic factors. Additionally, any current pain was significantly more common among PLHIV with symptoms of anxiety $(\mathrm{AOR}=2.49$; CI $95 \%$ $1.48,4.18, p<0.01)$ or PTSD (AOR $=1.69$; CI 95\% 1.11, 2.57, $p=0.02$ ) compared to PLHIV without those factors. Factors including race/ethnicity, marijuana use, and depression were not significantly associated with any current pain.

Table 3 Multivariate Analysis of Selected Covariates of Any Current Pain vs No Pain Among PLHIV N=733

\begin{tabular}{lll}
\hline Predictor & Any Pain vs. No pain & $P$ \\
\cline { 2 - 3 } & Adjusted $\mathrm{OR}^{1} \quad 95 \% \mathrm{Cl}^{2}$ & value \\
\hline
\end{tabular}

Age in Years

$18-49$

$\geq 50$

1.73

Referent

Sex

Male

Female

1.47

1.01

2.12

2.45

1.23

.45

$<0.01$

Race/Ethnicity

Non-Hispanic Black

Non-Hispanic White

Hispanic

1.40

0.82

Employment

Employed

Unemployed

Anxiety (GAD-7)

No $(<10)$

Yes $(\geq 10)$

Depression (PHQ-8)

No

Yes

0.95

1.63

1.08

2.45

0.02

Referent

2.49

1.48

4.18

Referent

0.57

1.59

0.86

Post-Traumatic Stress Disorder (PC-PTSD)

\begin{tabular}{lllll} 
No & \multicolumn{5}{c}{ Referent } \\
Yes & $\mathbf{1 . 6 9}$ & $\mathbf{1 . 1 1}$ & $\mathbf{2 . 5 7}$ & $\mathbf{0 . 0 1}$ \\
Marijuana Use & & & & \\
$\quad$ No use & & Referent & & \\
$\quad$ Recreational use & 1.07 & 0.70 & 1.65 & 0.74 \\
$\quad$ Therapeutic use & 1.55 & 0.95 & 2.53 & 0.08 \\
\hline${ }^{1} O R$ Odds Ratio & & & &
\end{tabular}

\section{Severe pain vs non-severe pain}

Results of the adjusted odds ratio of selected factors associated with severe pain are presented in Table 4. Pain was significantly more common in persons $\geq 50$ years of age $(\mathrm{AOR}=1.70$; $\mathrm{CI} 95 \% 1.07,2.72, p=0.03)$, females $(\mathrm{AOR}=2.02$; $\mathrm{CI} 95 \% 1.26,3.24, p<0.01)$, and participants reporting current symptoms of anxiety $(\mathrm{AOR}=$ 2.03; CI 95\% 1.03, 4.01, $p=0.04$ ) compared to individuals without those factors. On the contrary, pain was protective among Hispanic participants $(\mathrm{AOR}=0.48$; CI $95 \% 0.24,0.96, p=0.04$ ) compared to non-Hispanic Black participants. Factors including marijuana use, employment, depression, and PTSD were not statistically associated with severe pain.

Table 4 Multivariate Analysis of Selected Covariates of Severe Pain Among PLHIV N=733

\begin{tabular}{|c|c|c|c|c|}
\hline \multirow[t]{2}{*}{ Predictor } & \multicolumn{3}{|c|}{ Non-Severe Pain vs Severe Pain } & \multirow{2}{*}{$\begin{array}{l}P \\
\text { Value }\end{array}$} \\
\hline & Adjusted OR ${ }^{1}$ & $95 \% \mathrm{Cl}^{2}$ & & \\
\hline \multicolumn{5}{|l|}{ Age in years } \\
\hline $18-49$ & & Referent & & \\
\hline$\geq 50$ & 1.70 & 1.07 & 2.72 & 0.03 \\
\hline \multicolumn{5}{|l|}{ Sex } \\
\hline \multicolumn{5}{|l|}{ Male } \\
\hline Female & 2.02 & 1.26 & 3.24 & $<0.01$ \\
\hline \multicolumn{5}{|l|}{ Race/Ethnicity } \\
\hline Non-Hispanic Black & & Referent & & \\
\hline Non-Hispanic White & 0.58 & 0.32 & 1.06 & 0.08 \\
\hline Hispanic & 0.48 & 0.24 & 0.96 & 0.04 \\
\hline \multicolumn{5}{|l|}{ Employment } \\
\hline Employed & & Referent & & \\
\hline Unemployed & 1.87 & 0.96 & 3.65 & 0.07 \\
\hline \multicolumn{5}{|l|}{ Anxiety (GAD-7) } \\
\hline No $(<10)$ & & Referent & & \\
\hline Yes $(\geq 10)$ & 2.03 & 1.03 & 4.01 & 0.04 \\
\hline \multicolumn{5}{|l|}{ Depression (PHQ-8) } \\
\hline No & & Referent & & \\
\hline Yes & 1.29 & 0.66 & 2.52 & 0.46 \\
\hline
\end{tabular}

Post-Traumatic Stress Disorder (PC-PTSD)

\begin{tabular}{lllll} 
No & \multicolumn{5}{c}{ Referent } \\
Yes & 1.58 & 0.93 & 2.70 & 0.10 \\
Marijuana Use & & & & \\
No use & & Referent & & \\
Recreational use & 1.53 & 0.86 & 2.71 & 0.15 \\
Therapeutic use & 1.55 & 0.84 & 2.85 & 0.16 \\
\hline
\end{tabular}

${ }^{1} O R$ Odds Ratio

${ }^{2} \mathrm{Cl}$ Confidence Interval 


\section{Discussion}

This study sought to examine the prevalence of pain in a statewide sample of PLHIV and identify mental health, substance use, and sociodemographic factors associated with having any pain and having severe pain among PLHIV. Our results indicated that roughly half of our sample reported having any pain while $16.1 \%$ reported having severe pain during the previous $24 \mathrm{~h}$. Having any pain was positively associated with being older in age, female, unemployed, having current symptoms of anxiety, and PTSD. Additionally, having severe pain was positively associated with being older, female, and having current symptoms of anxiety. As such, the results of this analysis may serve as the foundation for developing pain interventions among PLHIV.

Treating pain among PLHIV is often challenging, as providers may be reluctant to prescribe opioid analgesics for this population [12]. Consequently, researchers have developed nonpharmaceutical approaches to reduce pain among PLHIV. Brandt and colleagues noted PLHIV may benefit from cognitive behavioral therapies (CBTs) targeting pain, depression, and anxiety [34]. CBTs can provide HIV patients with both effective strategies to help manage physical pain (i.e., relaxation strategies and activity pacing), as well as tools to help improve pain outlook, pain acceptance, and pain catastrophizing (e.g., anticipating the worst outcomes), correlates of the physical, occupational, and social consequences of pain [35]. Thus, care providers may consider implementing CBT as a way to reduce pain and adverse mental health outcomes among PLHIV.

\section{Mental health}

Psychological health factors associated with pain are a key concern, as PLHIV are more likely to be diagnosed with anxiety compared to the general population [36]. Our analysis noted symptoms of anxiety were associated with having any pain and severe pain, while symptoms of PTSD were associated with having any pain. These findings indicate a continued clinical need to address psychological distress among PLHIV as previous research has indicated a bidirectional relationship between pain and psychological distress [37]. Our analyses were not able to determine whether the pain, mental health, and substance abuse were causally influencing each other, or whether they could all be part of a common underlying health issue. If pain is contributing to the feelings of anxiety or to the desire to use drugs or alcohol, then treatment of pain may reduce these other symptoms. Nevertheless, it is also possible there is a common underlying mechanism, such as allostatic load. Allostatic load is defined as the process by which life stressors can accumulate leading to the development of medical conditions and is often higher among individuals with chronic conditions such as HIV [38]. As allostatic load increases, demands of life stressors can increase, thus leading to both an increased risk of developing depression and pain. Moreover, psychotherapeutic methods have been shown to be effective in managing both pain and comorbid depression [39].

\section{Substance use}

After controlling for selected covariates, none of the substance use variables were statistically associated with pain. Initially, we expected marijuana use to be associated with pain as chronic pain is one of the leading reasons for starting medical marijuana [40]. Similarly, we thought alcohol may be associated with pain as a recently published qualitative study, Cook et al. concluded that PLHIV may engage in risky drinking, in order to manage physical pain [41]. A similar study by Merlin et al. also noted marijuana use was not statistically associated with reductions in pain among PLHIV [42]. However, studies investigating the associations between marijuana use and pain have reported reductions in pain severity among the general population [43]. Therefore, PLHIV using marijuana for therapeutic reasons may have effectively reduced pain. As such, further research is needed to better elucidate the relationships between marijuana use for pain among PLHIV.

\section{Sociodemographics}

Our study noted that older individuals were more likely to report having any pain and severe pain compared to their younger counterparts. Generally, as people age, they become more likely to report pain. Thus, older PLHIV may be more likely to report nociceptive pain unrelated to HIV status. Additionally, older PLHIV are more likely to report musculoskeletal pain disorders compared to younger individuals. Musculoskeletal pain disorders including arthritis often present with inflammation which may generally be harder to treat, thus resulting in greater pain severity [44]. Women PLHIV were more likely to report having both any pain and severe pain compared to male PLHIV [45]. Furthermore, women often exhibit lower pain thresholds in experimental studies which may explain the increased pain severity in our analysis [46]. Lastly, PLHIV who reported being unemployed were more likely to report having any pain compared to employed individuals. Unemployed individuals may not be insured suggesting unemployed PLHIV may not receive adequate treatment for their pain [47]. Additionally, PLHIV may be unable to work due to their pain, which could adversely affect quality of life.

\section{Peak-end phenomenon}

In order to better control for recall bias and to control for the peak-end phenomenon, we were especially interested in understanding correlates of severe pain 
intensity. The peak-end phenomenon acknowledges that participant memory wains over time; thus, asking common questions including, "How has your pain been during the past week?" may not adequately capture participants' pain score [24]. In order to overcome this limitation, we differentiated worse pain intensity by using optimal cut-points from similar studies [30]. Our analysis noted that older age, being female, and having symptoms of anxiety were associated with severe pain. These results suggest that targeting modifiable risk factors for pain, specifically, anxiety may be a crucial step in reducing pain intensity among PLHIV.

\section{Limitations}

A few study limitations are worth discussing. In the current study, the cross-sectional design limits our ability to determine temporality between pain severity and correlates of mental health and substance use. While various recruitment methods were employed, the generalizability of the results may not be applicable to those with private insurance and PLHIV who do not seek healthcare services. Furthermore, we utilized a single measure of pain reliant upon a numerical scale to assess the magnitude of pain and thus may have failed to capture other aspects of pain such as the impact of pain on functioning, or the classification of pain (e.g., neuropathic, somatic). Additional research could incorporate broader measures of pain such as the Neuropathic Pain Scale [48] or the McGill Pain Questionnaire [49] in order to assess the classification of pain as well to measure pain severity. Finally, longitudinal studies are needed in order to better understand the temporal associations between severe pain and various psychosocial factors experienced by older PLHIV who now are living longer because of ART.

\section{Conclusions}

Our study noted roughly half of our participants repored any current pain in the past $24 \mathrm{~h}$. This study contributes to the growing literature on pain among PLHIV by demonstrating that the overlap of syndemic mental health and substance use is associated with increased pain among PLHIV. Additionally, this study identifies modifiable syndemic health factors associated with pain, which may serve as targets for pain interventions. As this trend continues, HIV care providers and researchers should seek to address mental health and drug use correlates of pain among this population.

\section{Abbreviations}

ART: Antiretroviral Therapy; HIV: Human Immunodeficiency Virus; PLHIV: People living with HIV/AIDS; IRB: Institutional Review Board; DoH: Florida Department of Health; HIPPA: Health Insurance Portability and Accountability Act; OR: Odds Ratio; Cl: 95\% Confidence Interval

\section{Acknowledgements}

We would like to thank the participants for their role in the study.

\section{Authors' contributions}

VJ analyzed and was a major contributor in writing the manuscript. AJ contributed to manuscript writing and interpretation of results. SC contributed to manuscript writing and interpretation of results. ZM contributed to manuscript writing and interpretation of results. $\mathrm{HL}$ contributed to the analysis and interpretation of results. NE contributed to manuscript writing and interpretation of results. Gl contributed to manuscript writing and interpretation of results. CS contributed to manuscript writing and interpretation of results. RC conceptualized the study and contributed to manuscript writing and interpretation of results. All authors read and approved the final manuscript.

\section{Funding}

This study received financial support from the National Institutes of Health grants 1U24AA02002-01 and F31DA047200 from the National Institute on Alcohol Abuse and Alcoholism (NIAAA) \& the National Institute of Drug Abuse (NIDA). The funding sources had no role in the study design, data collection, analysis, interpretation, or decisions to publish the findings.

\section{Availability of data and materials}

The datasets used and/or analyzed during the current study are available from the corresponding author on reasonable request.

\section{Ethics approval and consent to participate}

The protocol was approved by the Institutional Review Boards (IRBs) at the University of Florida and the Florida Department of Health (DoH). All participants provided written informed consent as well as signed the Health Insurance Portability and Accountability Act (HIPPA) authorization form for use of their protected medical information.

\section{Consent for publication}

Not applicable.

\section{Competing interests}

The authors declare that they have no competing interests.

\section{Author details}

${ }^{1}$ Department of Epidemiology, College of Public Health and Health Professions \& College of Medicine, University of Florida, P.O. Box 100231, 2004 Mowry Road, Gainesville, FL 32610, USA. ²Department of Health, Behavior, and Society, Bloomberg School of Public Health, Johns Hopkins University, 615 N Wolfe St, Baltimore, MD 21205, USA. ${ }^{3}$ Department of Clinical and Health Psychology, College of Public Health and Health Professions, University of Florida, P.O. Box 100231, 2004 Mowry Road, Gainesville, FL 32610, USA. ${ }^{4}$ Fred Hutchinson Cancer Research Center, University of Washington, 1100 Fairview Ave N, Seattle, WA 98109, USA. ${ }^{5}$ Department of Behavioral Sciences and Social Medicine, Center for Translational Behavioral Sciences, College of Medicine, Florida State University, 2010 Levy Ave, Bldg. B, suite 266, Tallahassee, FL 32310, USA. ${ }^{6}$ Department of Epidemiology, Florida International University, 11200 S.W. 8th Street, Building AHC-5, Room 478, Miami, Florida 33199, USA. ${ }^{7}$ Division of Infectious Disease and International Medicine, Morsani College of Medicine, University of South Florida, 12901 Bruce B Downs Blvd, Tampa, FL 33612, USA.

Received: 20 January 2020 Accepted: 30 August 2020

Published online: 18 September 2020

\section{References}

1. Wandeler G, Johnson LF, Egger M. Trends in life expectancy of HIV-positive adults on antiretroviral therapy across the globe: comparisons with general population: Current opinion in HIV and AIDS. U.S. National Library of Medicine; 2016. https://europepmc.org/article/med/27254748, https://doi. org/10.1097/coh.0000000000000298.

2. Mitchell MM, Isenberg SR, Maragh-Bass AC, Knowlton AR. Chronic pain predicting reciprocity of support among vulnerable, predominantly AfricanAmerican persons living with HIV/AIDS: SpringerLink. Springer US; 2017. 
https://pubmed.ncbi.nlm.nih.gov/28451889/, https://doi.org/10.1007/s10461017-1775-9.

3. Merlin JS, Childers J, Arnold RM. Chronic Pain in the Outpatient Palliative Care Clinic - Jessica S. Merlin, Julie Childers, Robert M. Arnold, 2013 . SAGE Journals 2013.

4. Silva JGD, Morgan DADR, Melo FCM, Santos IKD, Azevedo KPMD, Medeiros HJD, et al. Level of pain and quality of life of people living with HIV/AIDS pain and quality of life in HIV/AIDS. AIDS Care. 2017;29(8):1041-8.

5. Krasenbaum $\sqcup$. A review of HIV and headache: a cross-sectional study. Headache. 2017;57(10):1631-2.

6. Uebelacker LA, Weisberg RB, Herman DS, Bailey GL, Pinkston-Camp MM, Stein MD. Chronic pain in HIV-infected patients: relationship to depression, substance use, and mental health and pain treatment. Pain Med. 2015;16: 1870-81. https://doi.org/10.1111/pme.12799.

7. Safo SA, Blank AE, Cunningham CO, Quinlivan EB, Lincoln T, Blackstock OJ. Pain is associated with missed clinic visits among HIV-positive women. AIDS Behav. 2016;21:1782-90. https://doi.org/10.1007/s10461-016-1475-x.

8. Tsui Jl, Cheng DM, Quinn E, Bridden C, Merlin JS, Saitz R, et al. Pain and mortality risk in a Cohort of HIV-infected persons with alcohol use disorders. AIDS Behav. 2015;20:583-9. https://doi.org/10.1007/s10461-015-1206-8.

9. Mitchell MM, Nguyen TQ, Maragh-Bass AC, Isenberg SR, Beach MC, Knowlton AR. Patient-provider engagement and chronic pain in drug-using, primarily African American persons living with HIV/AIDS. AIDS Behav. 2016; 21:1768-74. https://doi.org/10.1007/s10461-016-1592-6.

10. Brandt CP, Zvolensky MJ, Daumas SD, Grover KW, Gonzalez A. Pain-related anxiety in relation to anxiety and depression among persons living with HIV/AIDS. AIDS Care. 2015;28:432-5. https://doi.org/10.1080/09540121.2015. 1100704.

11. Merlin JS, Tamhane A, Starrels JL, Kertesz S, Saag M, Cropsey K. Factors associated with prescription of opioids and co-prescription of sedating medications in individuals with HIV. AIDS Behav. 2015;20:687-98. https://doi. org/10.1007/s10461-015-1178-8.

12. Hser Y-I, Mooney LJ, Saxon AJ, Miotto K, Bell DS, Huang D. Chronic pain among patients with opioid use disorder: results from electronic health records data. J Subst Abus Treat. 2017;77:26-30. https://doi.org/10.1016/j.jsat. 2017.03.006.

13. Sharma A, Hoover DR, Shi Q, Tsao JCl, Cox C, Gustafson DR, et al. Frequent occurrence of pain and prescription opioid use for treatment of pain among women with and at risk for HIV infection. AIDS Behav. 2017;22:200817. https://doi.org/10.1007/s10461-017-1828-0.

14. Larowe LR, Chilcott LN, Zvolensky MJ, Vanable PA, Flood K, Ditre JW. Associations between pain-related anxiety, gender, and prescription opioid misuse among tobacco smokers living with HIV/AIDS. Subst Use Misuse. 2018;53(13):2210-9.

15. Merlin J, Bair M, Kerns R, Burgio K, Turan J. (495) Pain self-management in HIV-infected individuals with chronic pain: a qualitative study. J Pain. 2015; 16(4)::706-14.

16. Millar BM, Starks TJ, Gurung S, Parsons JT. The impact of comorbidities, depression, and substance use problems on quality of life among older adults living with HIV. AIDS Behav. 2016;21(6):1684-90.

17. Jones JD, Vogelman JS, Luba R, Mumtaz M, Comer SD. Chronic pain and opioid abuse: factors associated with health-related quality of life. Am J Addict. 2017;26(8):815-21.

18. Evangeli M. Mental health and substance use in HIV-infected adolescents. Curr Opin HIV AIDS. 2018;13(3):204-11.

19. Felker-Kantor EA, Wallace ME, Madkour AS, Duncan DT, Andrinopoulos K, Theall K. HIV stigma, mental health, and alcohol use disorders among people living with HIV/AIDS in New Orleans. J Urban Health. 2019;96(6): 878-88.

20. Gibbs A, Jewkes R, Willan S, Washington L. Associations between poverty, mental health and substance use, gender power, and intimate partner violence amongst young (18-30) women and men in urban informal settlements in South Africa: A cross-sectional study and structural equation model. PLoS One. 2018;13(10).

21. National HIV/AIDS strategy for the United States: updated to 2020

22. Benoliel R, Kahn J, Eliav E. Peripheral painful traumatic trigeminal neuropathies. Oral Dis. 2011;18(4):317-32.

23. Mwesiga EK, Mugenyi L, Nakasujja N, Moore S, Kaddumukasa M, Sajatovic M. Depression with pain co morbidity effect on quality of life among HIV positive patients in Uganda: a cross sectional study. Health Qual Life Outcomes. 2015;13. https://doi.org/10.1186/s12955-015-0403-5.
24. Schneider S, Stone AA, Schwartz JE, Broderick JE. Peak and end effects in patients daily recall of pain and fatigue: a within-subjects analysis. J Pain. 2011;12:228-35. https://doi.org/10.1016/j.jpain.2010.07.001.

25. Florida Cohort. Southern HIV and Alcohol Research Consortium. http:// sharc-research.org/research/flcohort/. Published July 17, 2020. Accessed 6 Aug 2020.

26. Bendtsen P, Karlsson N, Dalal K, Nilsen P. Hazardous drinking concepts, limits and methods: low levels of awareness, knowledge and use in the Swedish population. Alcohol Alcohol. 2011;46:638-45. https://doi.org/10 1093/alcalc/agr065.

27. Schauer GL, King BA, Bunnell RE, Promoff G, Mcafee TA. Toking, Vaping, and eating for health or fun. Am J Prev Med. 2016;50(1):1-8. https://doi.org/10. 1016/j.amepre.2015.05.027.

28. Daut RL, Cleeland CS, Flanery RC. Development of the Wisconsin brief pain questionnaire to assess pain in cancer and other diseases. Pain. 1983;17(2): 197-210.

29. Cleeland CS Ryan KM. Pain assessment: global use of the Brief Pain Inventory. Ann Acad Med Singapore (1994 Mar) 23(2):129-38. Rehabilitation Oncology 1995;13:29-30. doi:https://doi.org/10.1097/01893697-19951301000022.

30. Li KK, Harris K, Hadi S, Chow E. What should be the optimal cut points for mild, moderate, and severe pain? J Palliat Med. 2007;10:1338-46. https://doi. org/10.1089/jpm.2007.0087.

31. Shacham E, Morgan JC, Önen NF, Taniguchi T, Overton ET. Screening anxiety in the HIV clinic. AIDS Behav. 2012;16:2407-13. https://doi.org/10. 1007/s10461-012-0238-6.

32. Kroenke K, Strine TW, Spitzer RL, Williams JB, Berry JT, Mokdad AH. The PHQ8 as a measure of current depression in the general population. J Affect Disord. 2009;114:163-73. https://doi.org/10.1016/j.jad.2008.06.026.

33. Prins A, Ouimette P, Kimerling R, Camerond RP, Hugelshofer DS, ShawHegwer J, et al. The primary care PTSD screen (PC-PTSD): development and operating characteristics. Prim Care Psychiatry. 2004;9:9-14. https://doi.org/ 10.1185/135525703125002360.

34. Brandt CP, Paulus DJ, Garza M, Lemaire C, Norton PJ, Zvolensky MJ. A novel integrated cognitive-behavioral therapy for anxiety and medication adherence among persons living with HIV/AIDS. Cogn Behav Pract. 2018; 25(1):105-18. https://doi.org/10.1016/j.cbpra.2017.01.007.

35. Gonzalez CE, Okunbor II, Parker R, et al. Pain-Specific Resilience in People Living With HIV and Chronic Pain: Beneficial Associations With Coping Strategies and Catastrophizing. Front Psychol. 2019;10:2046. Published 2019 Sep 6. https://doi.org/10.3389/fpsyg.2019.02046.

36. Bernard C, Dabis F, Rekeneire ND. Prevalence and factors associated with depression in people living with HIV in sub-Saharan Africa: a systematic review and meta-analysis. PLoS One. 2017;12. https://doi.org/10.1371/ journal.pone.0181960.

37. Kroenke K, Wu J, Bair MJ, Krebs EE, Damush TM, Tu W. Reciprocal relationship between pain and depression: a 12-month longitudinal analysis in primary care. J Pain. 2011;12(9):964-73. https://doi.org/10.1016/j.spinee. 2011.12.010 Epub 2011 Jun 16. Spine J 2012;12:84.

38. Veehof MM, Oskam M-J, Schreurs KM, Bohlmeijer ET. Acceptance-based interventions for the treatment of chronic pain: a systematic review and metaanalysis. Pain. 2011;152:533-42. https://doi.org/10.1016/j.pain.2010.11.002.

39. Damush T, Kroenke K, Bair M, Wu J, Tu W, Krebs E, et al. Pain selfmanagement training increases self-efficacy, self-management behaviours and pain and depression outcomes. Eur J Pain. 2016;20:1070-8. https://doi. org/10.1002/ejp.830.

40. Häuser W, Finn DP, Kalso E, Krcevski-Skvarc N, Kress H-G, Morlion B, et al. European pain federation (EFIC) position paper on appropriate use of cannabis-based medicines and medical cannabis for chronic pain management. Eur J Pain. 2018;22:1547-64. https://doi.org/10.1002/ejp.1297.

41. Cook RL, Cook CL, Karki M, Weber KM, Thoma KA, Loy CM, et al. Perceived benefits and negative consequences of alcohol consumption in women living with HIV: a qualitative study. BMC Public Health. 2016;16. https://doi. org/10.1186/s12889-016-2928-x.

42. Merlin JS, Long D, Becker WC, Cachay ER, Christopolous KA, Claborn KR, et al. Marijuana use is not associated with changes in opioid prescriptions or pain severity among people living with HIV and chronic pain. J Acquir Immune Defic Syndr. 2019:81:231-7. https://doi.org/10.1097/qai. 0000000000001998.

43. Poli P, Crestani F, Salvadori C, Valenti I, Sannino C. Medical Cannabis in patients with chronic pain: effect on pain relief, pain disability, and 
psychological aspects. A Prospective Non randomized Single Arm Clinical Trial. Clin Ter. 2018. https://doi.org/10.7417/T.2018.2062.

44. Abdelhamid RE, Sluka KA. ASICs mediate pain and inflammation in musculoskeletal diseases. Physiology. 2015;30:449-59. https://doi.org/10. 1152/physiol.00030.2015.

45. Miaskowski C, Penko JM, Guzman D, Mattson JE, Bangsberg DR, Kushel MB. Occurrence and characteristics of chronic pain in a community-based Cohort of indigent adults living with HIV infection. J Pain. 2011;12:1004-16. https://doi.org/10.1016/j.jpain.2011.04.002.

46. Maurer AJ, Lissounov A, Knezevic I, Candido KD, Knezevic NN. Pain and sex hormones: a review of current understanding. Pain Manag. 2016;6:285-96. https://doi.org/10.2217/pmt-2015-0002.

47. Webel AR, Wantland D, Rose CD, Kemppainen J, Holzemer WL, Chen W-T, et al. A cross-sectional relationship between social capital, self-compassion, and perceived HIV symptoms. J Pain Symptom Manag. 2015;50:59-68. https://doi.org/10.1016/j.jpainsymman.2014.12.013.

48. Galer BS, Jensen MP. Development and preliminary validation of a pain measure specific to neuropathic pain: The Neuropathic Pain Scale. Neurology. 1997:48(2):332-8.

49. Melzack R. The short-form McGill pain questionnaire. Pain. 1987;30(2):191-7.

\section{Publisher's Note}

Springer Nature remains neutral with regard to jurisdictional claims in published maps and institutional affiliations.

Ready to submit your research? Choose BMC and benefit from:

- fast, convenient online submission

- thorough peer review by experienced researchers in your field

- rapid publication on acceptance

- support for research data, including large and complex data types

- gold Open Access which fosters wider collaboration and increased citations

- maximum visibility for your research: over $100 \mathrm{M}$ website views per year

At BMC, research is always in progress.

Learn more biomedcentral.com/submissions 